\title{
Kebertahanan Usaha Kain Batik di Desa Gulurejo Tahun 1986-2018
}

\author{
Bima Alqari Malibari*, Ida Ayu Putu Mahyuni, A.A.A. Dewi Girindra Wardani \\ Prodi Sejarah, Fakultas Ilmu Budaya, Unud \\ [bimaalqarim@gmail.com], [iamahyuni@gmail.com],[dewigirindra69@gmail.com] \\ Denpasar, Bali, Indonesia \\ *Corresponding Author
}

\begin{abstract}
This research entitled The Development of Batik Fabric Enterprises in Gulurejo Village, Lendah District, Kulon Progo Regency, Yogyakarta Special Region 1986-2018. The purpose of this research is to determine the development of batik fabric business in the village of Gulurejo, what factors influenced the development of the batik fabric business and the implications of the development of batik fabric business for the local community. In this the researcher apply the methodology of economic history. The theory used in this research is the theory of Jhon Adam Smith about demand and supply, besides that the researcher also use the theory of commodification from Marx. The method used in this research is historical research method, where in this method there are four stages namely, (1) heuristic, (2) Source Criticism, (3) interpretation, and (4) historiography. The results of this study revealed the ups and downs of the batik cloth business were influenced by several events such as the economic crisis, the Bali bombings and the earthquake. The development of batik cloth business is influenced by the community and government policies. With the development of the batik cloth business until 2018 it has had an impact on society in the socio-economic and socio-cultural fields.
\end{abstract}

\section{Keywords: Batik Fabric, Development, Survival}

\begin{abstract}
Abstrak
Penelitian ini berjudul Perkembangan Usaha Kain Batik di Desa Gulurejo, Kecamatan Lendah, Kabupaten Kulon Progo, Daerah Istimewa Yogyakarta 1986-2018. Tujuan dari penelitian ini adalah untuk mengetahui perkembangan usaha kain batik di Desa Gulurejo, faktor-faktor apa saja yang mempengaruhi berkembangnya usaha kain batik dan implikasi dari berkembangnya usaha kain batik terhadap masyarakat lokal. Dalam penelitian ini menggunakan metodologi sejarah ekonomi. Teori yang digunakan dalam penelitian ini merupakan teori dari Jhon Adam Smith tentang permintaan dan penawaran, selain itu juga digunakan teori komodifikasi dari Marx. Metode yang digunakan dalam penelitian ini adalah metode penelitian sejarah, dimana dalam metode ini terdapat empat tahapan yaitu, (1) heuristic, (2) Kritik Sumber, (3) interpretasi, dan (4) historiografi. Hasil penelitian ini mengungkapkan naik dan turunnya usaha kain batik dipengaruhi oleh beberapa peristiwa seperti krisis ekonomi, bom Bali dan gempa bumi. Berkembangnya usaha kain batik dipengaruhi oleh masyarakat dan kebijakan pemerintah. Dengan berkembangnya usaha kain batik hingga tahun 2018 telah memberikann dampak terhadap masyarakat di bidang sosial ekonomi dan sosial budaya.
\end{abstract}

Kata Kunci : Kain Batik, Perkembangan, Kebertahanan

\section{PENDAHULUAN}

Kata batik adalah sebuah kata yang berasal dari kata Jawa, yang cara mengerjakannya dengan apa yang disebut sebagai cecek atau titik yang mengisi dalam sebuah bidang motif. Kata titik tersebutlah kemudian berubah menjadi kata tik dan cara melukisnya dengan lilin disebut membatik (H.J. Wibowo, 1990: 91). Pada awalnya batik hanya digunakan 
untuk pakaian raja-raja atau bangsawan di Jawa. Rakyat biasa dapat juga menggunakan batik namun dengan motif yang berbeda dengan milik para kaum elit. Hal ini karena fungsi penggunaan motif batik pada zaman dulu salah satunya adalah sebagai media untuk mengatur kehidupan sosial masyarakat dalam hal pembagian kelas atau strata sosial (Sumartono, 2009: 71).

Industri batik di daerah-daerah tertentu mempunyai corak, motif, dan gayanya sendiri yang khas. Contohnya batik Yogyakarta, batik Surakarta, batik Cirebon, dan batik Pekalongan. Mereka memiliki perbedaan motif, corak, dan pewarnaannya (Yudi Prasetyo, 2017). Batik yang berasal dari Kabupaten Kulon Progo Yogyakarta juga memiliki ciri khas tersendiri dibandingkan dengan batik dari daerah lain. Motif khas batik yang dimiliki Kulon Progo adalah geblek renteng. Pusat industri kain batik di Kulon Progo berada di Desa Gulurejo Kecamatan Lendah. Selain bertani, membatik juga merupakan salah satu pekerjaan masyarakat Gulurejo sejak dahulu. Dulunya mereka ada yang ke kota untuk menjadi buruh batik dan ada juga yang membatik di rumah lalu di jual pada para pengepul.

Pengembangan (UMK) menjadi satu bentuk tujuan utama dalam usaha pembangunan ekonomi nasional. Dari usaha ini tidak hanya bertujuan untuk meminimalisir masalah perbedaan pendapatan buruh dengan pemilik usaha, atau pengurangan angka kemiskinan dan peluasan lapangan tenaga kerja (Musran Muniz, 2010: 33).

Kemajuan industri batik di Desa Gulurejo juga tidak lepas dari campur tangan pemerintah setempat. Salah satu program dari pemerintah daerah berdampak besar dalam kemajuan industri kain batik di Desa Gulurejo adalah bela beli Kulon Progo. Program tersebut dikeluarkan oleh Bupati Kulon Progo dan wakilnya, tanggal 25 bulan
Maret tahun 2013 lalu. Program ini merupakan sebuah tindakan bersamasama untuk membeli produk-produk lokal. Kegiatan tambahan atau ekstrakurikuler seperti membatik juga dilakukan di Sekolah-sekolah Lendah, sekolah secara umum, menekankan bahwa guru tersebut mampu membatik dan mengajarkan batik kepada peserta didik. Oleh karena itu, sekolah merekrut guru pembimbing yang berlatar belakang seorang pengrajin batik di Desa Gulurejo, Lendah (Aurora Agasi, E-Jurnal)

Di Desa Gulurejo, sampai saat ini terdapat 15 pengusaha kain batik yang masih aktif memproduksi kain batik. Tenaga kerja rata-rata adalah penduduk atau masyarakat Desa Gulurejo. Dengan awal berdirinya satu industri pertama di Desa Gulurejo pada tahun 1986 berkembang hingga saat ini menjadi lima belas industri dan menjadi sentral batik Kulon Progo. Tulisan ini akan menyajikan perkembangan usaha kain batik yang ada di Desa Gulurejo dari tahun 1986 hingga 2018. Tahun 1986 diambil sebagai awal penulisan karena pada tahun 1986, awal berdirinya satu industri pertama di Desa Gulurejo. Tahun 2018 dipakai sebagai batasan akhir dari penulisan ini, karena tahun 2018 industri kain batik di Desa Gulurejo masih terus berkembang dan tetap eksis.

Berdasarkan latar belakang diatas, adapun kajian yang diteliti oleh penulis adalah mengenai perkembangan usaha kain batik di Desa Gulurejo. Berkaitan dengan kajian tersebut, maka dapat diformulasikan dalam tiga buah pertanyaan penelitian yakni : 1) Bagaimana perkembangan usaha kain batik yang ada di Gulurejo ? 2) Faktorfaktor apa yang menyebabkan berkembangnya usaha kain batik di Desa Gulurejo ? 3) Apa implikasi dari perkembangan usaha kain batik di Desa Gulurejo bagi masyarakat lokal ? 


\section{METODE}

Metodologi bisa diartikan sebagai ilmu atau sebuah kajian tentang metode, menganalisa prinsip atau tahapan yang menuntun penyelidikan dalam sebuah kajian yang akan di teliti (Helius Sjamsuddin, 2016: 10). Dalam proses analisisa, seorang peneliti memerlukan alat bantu yang nantinya dibutuhkan untuk memudahkan proses analisis, alatalat analisis harus memenuhi syaratsyarat sehingga dapat berfungsi secara operasional, relevan dan cocok dengan objek yang akan dikaji. (Sartono Kartodirjo, 2017: 2). Sejarah ekonomi didalam penelitian ini dijadikan sebagai metodologi. Menurut Barry E. Supple mengatakan bahwa, sejarah ekonomi adalah studi sejarah tentang upaya manusia untuk menyediakan barang dan jasa, tentang hubungan dengan suatu lembaga atau badan usaha, tentang pandangan dan teknik yang berhubungan dengan usaha ekonomi (Kuntowijoyo, 2003: 94).

Metode sejarah sebagai sebuah tahapan untuk menguji dan menganalisis keaslian sumber-sumber sejarah seperti dokumen. rekaman, dan peninggalanpeninggalan sejarah lainnya yang autentik, dan dapat menciptakan interpretasi dan sintesis dari fakta yang telah diketemukan tersebut menjadi sebuah cerita sejarah yang kebenarannya siap diujikan (Daliman, 2018: 25).

\section{KERANGKA TEORI}

Untuk mendukung penelitian ini maka digunakan beberapa literatur berupa skripsi sebagai acuan antara lain: 1) Skripsi yang berjudul "Dinamika Pengrajin Kain Batik di Wijirejo, Pandak, Kabupaten Bantul 1960-1997" yang ditulis oleh Rudy Rahman Wiryatama. 2) Skripsi yang berjudul "Upaya Pengembangan Pengrajin Batik di Desa Wisata Batik Gulurejo Kecamatan Lendah Kabupaten Kulon Progo" yang ditulis oleh Yosi Wulandari.
3) Skripsi yang berjudul "Perkembangan Industri Kerajinan Tenun Ikat Di Desa Parengan Kecamatan Maduran Kabupaten Lamongan, Jawa Timur Tahun 1950-2007" yang ditulis oleh Fibri Arsitandi. 4) Skripsi yang berjudul "Dinamika Ekspor Komoditas Industri Kerajinan Bali Tahun 1990-2015" yang ditulis oleh Wandi Fransiskus Samosir.

Untuk terciptanya satu penulisan yang baik, oleh karena itu dalam melakukan suatu analisa dan pengkajian terhadap beberapa permasalahan yang ditemukan nantinya, akan digunakan metode sejarah dan teori sejarah. Teori sejarah akan memberikan tuntunan bagi seorang sejarawan untuk mendapatkan hasil penulisan sejarah yang dapat dijadikan sebagai pengetahuan yang tersusun secara metodis dan sistematis.

Dalam penelitian ini menggunakan teori ekonomi mikro yang diperkenalkan oleh Jhon Adam Smith. Adam Smith dengan tajam menganalisis proses terbentukya harga di pasar oleh interaksi antara pembeli (permintaan) dan penjual (penawaran, biaya produksi). Berkaitan dengan uraian diatas, teori komodifikasi digunakan dalam penelitian ini. Komodifikasi asal kata komoditas, dan Marx memberi makna segala yang diproduksi dan diperjual belikan. Komodifikasi dapat diartikan proses menjadikan sesuatu yang tadinyanya bukanlah sebuah komoditi, setelah diproses menjadi komoditi.

\section{HASIL DAN PEMBAHASAN}

\section{Perkembangan Usaha Kain Batik di Desa Gulurejo}

Usaha kain batik di Gulurejo mulai berdiri tahun 1986. Sebelumnya para pengrajin ini hanya seorang buruh batik di kota Yogyakarta. Mulai dari hanya satu orang dan terus berkembang hingga tahun 2018 sudah ada lima belas pengusaha kain batik. Untuk mengawali usaha kain batik para pengrajin hanya 
menggunakan modal milik mereka sendiri dan bukan dari hasil pinjaman. Modal yang dikeluarkann untuk memulai produksi kain batik berkisar 2.000.00010.000 .000 rupiah. Selain itu tenaga kerja atau buruh batik juga dari keluarga dan tetangga pengrajin sendiri.

Dalam perkembangannya, usaha kain batik di Desa Gulurejo mengalami timbul dan tenggelam atau bisa disebut juga pasang surut penjualan kain batik. Beberapa peristiwa seperti krisis ekonomi, bom Bali, dan gempa bumi Bantul dapat memberikan dampak dalam perkembangan usaha kain batik. Peristiwa-peristiwa tersebut telah menyebabkan menurunnya penghasilan pengrajin, hal ini karena mereka kesulitan menjual hasil produksi. Pengrajin bahkan sampai sempat memberhentikan produksinya dan beralih ke profesi lain untuk memenuhi kebutuhan hidupnya.

Kesuksesan usaha kain batik baru mulai dirasakan oleh para pengrajin mulai dari tahun 2009. Penjualan kain batik meningkat setelah batik dinyatakan oleh UNESCO, batik dinyatakan sebagai budaya tak benda warisan manusia. Peristiwa ini diikuti dengan keluarnya Keputusan Presidan No. 33 Tahun 2009 tentang Hari Batik Nasional (Ihyaul Ulum, 2016: 28). Sejak peristiwa ini batik menjadi lekat sebagai salah satu tanda untuk menampilkan citra nasionalis. Pemerintah dan kebanyakan perusahaan menetapkan satu hari khusus dalam satu minggu dimana para pegawai harus memakai batik (Angela Oscario, 2014: 552). Selain itu adanya program dari pemerintah daerah yaitu bela dan beli Kulon Progo yang digalakkan oleh Bupati pada Maret 2013 (Felix Arberd Nur Kristianto, 2015: 21). Program tersebut adalah gerakan untuk membeli produk lokal saja (Elson G. Budi Susilo, 2017: 4). Omzet penjualan kain batik motif geblek renteng mengalami peningkatan menjelang peringatan Hari
Batik Nasional dan tahun ajaran baru sekolah. Karena sekolah-sekolah di Kulon Progo mewajibkan batik geblek renteng sebagai salah satu seragam sekolah.

Motif batik geblek renteng merupakan motif khas pertama Kulon Progo, sejak tahun 2012 hingga 2018 menjadi motif kain terlaris di setiap tahun (Yeni Priandani, 2017: 540). Motif geblek renteng ini menjadi motif yang paling banyak diproduksi oleh pengrajin batik di Desa Gulurejo, hampir sebagian produksi pengrajin bermotif geblek renteng. Meskipun kebanyakan motifnya hampir sama antara satu pengrajin dengan pengrajin lainnya, tetap saja hasil kain batik yang telah diproduksi tetap berbeda antara pengrajin satu dan yang lainnya. Ini terjadi karena adanya krativitas dari pengrajin, seperti pemberian isian yang sesuai dengan ide pengrajin, selain itu teknik pewarnaan juga menjadi ciri khas yang dimiliki oleh para pengrajin kain batik.

\section{Faktor-Faktor Yang Mempengaruhi Berkembangnya Usaha Kain Batik di Desa Gulurejo}

Berkembangnya usaha kain batik di Desa Gulurejo disebabkan oleh berbagai faktor. Pertama adalah sumber daya manusia di Desa Gulurejo yang memiliki watak kerja keras dan memiliki kemauan untuk belajar membatik. Selain itu kain batik sebagai suatu komoditas juga menjadi faktor yang menyebabkan berkembangnya usaha kain batik di Desa Gulurejo.

Produk juga bisa diklasifikasikan berdasarkan kebiasaan konsumen dalam membeli produk antara lain 1) Barang kenyamanan 2) Barang pilihan 3) Barang special (Bambang Sulistiyono, 2019: 8485). Kain batik diproduksi dan didistribusikan sendiri oleh pengrajin sesuai dengan permintaan konsumen atau pelanggan. Namun para pengrajin batik tetap menjaga kualitas barang produksi 
yang akan mereka jual. Dijadikannya Desa Gulurejo sebagai Desa Wisata Batik juga memberikan dampak dalam berkembangnya usaha kain batik (Yosi Wulandari, 2018). Desa wisata adalah salah satu bentuk pengembangan suatu wilayah tertentu, memaksimalkan potensi-potensi yang ada didalam masyarakat desa, nantinya dapat dijadikan menjadi produk-produk wisata. Desa tersebut juga wajib menyediakan dan melengkapi berbagai kebutuhan perjalanan wisata, mulai dari faktor daya tarik ataupun berbagai fasilitas-fasilita pendukung lainnya (Agus Muriawan Putra, 2012: 67). Desa wisata juga dapat diartikan suatu wilayah yang memiliki kearifan lokal budaya, adat-istiadat, dan hal unik yang ada, dan digunakan sebagai daya tarik (Hary Hermawan, 2016: 107).

Kain batik pengrajin menjadi lebih dikenal luas sehingga dapat memperluas pemasaran dan juga meningkatkan penghasilan para pengrajin batik. Para pengrajin batik Desa Gulurejo juga bergabung dalam kelompok batik Lendah. Dengan adanya kelompok ini, mereka memiliki wadah untuk mendapat informasi, menyelesaikan permasalahan yang ditemui pengrajin dalam usahanya dan meningkatkan solidaritas sesama pengrajin batik. Faktor terakhir yang menyebabkan berkembangnya usaha kain batik adalah Pemerintah Daerah Kulon Progo. Dengan bantuan pemerintah dan kebijakan-kebijakannya yang dianggap menguntungkan bagi para pengrajin kain batik di Desa Gulurejo.

\section{Implikasi Dari Berkembangnya Usaha Kain Batik Terhadap Mayarakat Lokal}

Dampak perkembangan usaha kain batik di Desa Gulurejo terhadap kehidupan masyarakat desa meliputi dampak di bidang sosial ekonomi dan bidang sosial budaya. Dampak dalam bidang sosial ekonomi ditunjukan dengan terciptanya lapangan tenaga kerja sebagai buruh batik. Terutama telah memberikan peluang kerja bagi perempuan (Gumirlang Wicaksono, 2012: 28), ibuibu rumah tangga dapat membawa kerjaannya ke rumah dengan sistem borongan, sehingga dapat dikerjakan di sela waktu yang mereka miliki (Dewi Suci Triningsih, 2018: 50). Adanya usaha kain batik ini juga telah menekan jumlah warga yang selama ini menjadi pengangguran, kesadaran wanita memaasuki pasar kerja didoronng oleh faktor ekonomi (Siti Maria, 2012: 56). Adanya desa wisata batik mendorong masyarakat Desa Gulurejo untuk bewiraswasta/wirausaha. Perekonomian yang membaik dan meningkat, akan meningkatkan status seseorang di dalam masyarakat. Penghasilan yang cukup bagi masyarakat, menyebabkan semakin baiknya tingkat pendidikan masyarakat dan perubahan pola dalam proses sosialisasi dikarenakan alat komunikasi yang canggih. Adanya perbedaan status di masyarakat yang tampak pada kepemilikan harta benda, pola interaksi, gaya hidup para pengusaha kain batik Gulurejo.

Dampak sosial budaya dari berkembangnya usaha kain batik di Desa Gulurejo adalah selametan yang diadakan setiap tanggal 2 Oktober sebagai wujud dari rasa syukur dengan majunya usaha kain batik. Selain itu setiap pada tanggal 17 Agustus masyarakat selalu mengikuti karnaval dalam perayaan hari kemerdekaan dengan menggunakan pakaian batik. Selain bertujuan untuk merayakan hari kemerdekaan juga untuk mengenalkan kain batik sebagai salah satu kekayaan budaya yang dimiliki Desa Gulurejo. Berkembangnya usaha kain batik juga menumbuhkan budaya kerja, karena kerja dianggap sesuatu yang memiliki nilai lebih dan menghasilkan. Kegiatan-kegiatan kemasyarakatan yang bersifat sosial, berubah menjadi sesuatu yang harus difikirkan terlebih dahulu untuk menjalankannya karena mereka 
lebih mengutamakan pekerjaan, dimana tampak adanya pergeseran nilai-nilai dari kegiatan sosial budaya ke arah perhitungan yang lebih ekonomis. Selain itu, berkembangnya usaha kain batik juga telah berpengaruh dalam pendidikan sekolah di kecamatan Lendah. Sekolahsekolah mulai dari SD, SMP, dan SM A di Lendah memberikan pelajaran membatik untuk siswanya sebagai tambahan keterampilan. Guru yang mengajar membatik adalah pengrajin yang berasal dari Desa Gulurejo.

\section{SIMPULAN}

Perkembangan usaha kain batik layaknya usaha lainnya, usaha ini juga mengalami masa timbul tenggelam atau naik dan turunnya penjualan. Perkembangan usaha kain batik juga dipengaruhi oleh keadaan politik, keamanan Negara dan faktor alam. Seperti yang telah diuraikan diatas bahwa krisis ekonomi, bom Bali dan gempa bumi Bantul mengakibatkan menurunnya omzet penjualan para pengrajin.

Selain sumber daya manusia faktor pendorong yang kuat adalah peran pemerintah daerah Kulon Progo dengan kebijakan-kebijakannya yang dapat dikatakan sangat menguntungkan para pengrajin batik di Desa Gulurejo.

Dengan Berkembangnya usaha kain batik di Desa Gulurejo telah menciptakan lapangan pekerjaan baru dan peluang berwirausaha, selain itu perkembangan usaha ini juga berpengaruh dalam bidang sosial budaya. Dimana muncul budayabudaya baru yang diakibatkan dengan berkembangnya usaha kain batik di Desa Gulurejo.

Pengrajin diharapkan ke depan nya lebih berani untuk mengajukan pinjaman untuk tambahan modal agar usaha menjadi lebih besar. Para pengrajin ke depan nya diharapkan lebih mengoptimalkan lagi penggunaan sosial media sebagai sarana pemasaran kain batik. Desa Wisata Batik Gulurejo memerlukan sebuah kepengurusan yang khusus untuk mengurusi desa wisata tersebut, supaya kedepannya desa wisata batik ini bisa lebih maju lagi Selain itu agar penelitian ini dapat menjadi acuan bagi para perajin kain batik dan pemerintah Kabupaten Kulon Progo agar ke depan nya perkembangan usaha kain batik terus meningkat.

\section{REFERENSI}

Agasi, Aurora. (2017). Pengelolaan Kegiatan Ekstrakurikuler Membatik di Sekolah Dasar se-Kecamatan Lendah Kabupaten Kulonprogo. Jurnal. Fakultas Ilmu Pendidikan Universitas Negeri Yogyakarta, Vol. 6, No. 5.

Daliman. (2018). Metode Penelitian Sejarah. Yogyakarta: Penerbit Ombak.

Kartodirdjo, Sartono. (2017). Pendekatan Ilmu Sosial dalam Metodologi Sejarah. Yogyakarta: Ombak.

Kristianto, Felix Arberd Nur. (2015). Partisipasi Masyarakat Kecamatan Kalibawang dalam Gerakan BelaBeli Kulon Progo. Jurnal. Fakultas Ilmu Sosial Universitas Negeri Yogyakarta, Vol. 12, No. 1.

Kuntowijoyo. (2003). Metodologi Sejarah. Yogyakarta: Tiara Wacana.

Maria, Siti. (2012). Faktor Pendorong Peningkatan Produktifitas Tenaga Kerja Wanita Sektor Industri, Perdagangan dan Jasa di Kalimantan Timur. Jurnal Forum Ekonomi Vol. XV, No. 2.

Oscario, Angela. (2014). Simulasi Citra Nasionalis Melalui Fashion: Studi Kasus Batik Printing Dalam Gaya 
Hidup Post Modern Masyarakat Kota. Jurnal. Binus University Jakarta, Vol. 5, No. 2.

Putra, Agus Muriawan. (2012). Konsep Desa Wisata. Jurnal Manajemen dan Pariwisata, Vol. 5, No. 1.

Sjamsuddin, Helius. 2016. Metodologi Sejarah. Yogyakarta: Ombak.

Sulistiyono, Bambang. (2019). IbM Pemberdayaan Kelompok Pengrajin Batik Kecamatan Lendah Kabupaten Kulon Progo DIY. Jurnal. Buletin Ekonomi UPN Yogyakarta, Vol. 15, No. 1.

Sumartono, dkk. (2009). Sejarah Kebudayaan Indonesia Seni Rupa dan Desain. Jakarta: PT RajaGrafindo Persada.

Susilo, Budi Elson G. (2017). Kajian Implementasi "Bela-Beli Kulon Progo" (Kasus: Air-ku, Batik Geblek Renteng, Dan Tomira). Jurnal. UGM, Vol. 6, No. 3.

Triningsih, Dewi Suci. (2018). Pengaruh Industri Batik Tjokro di Kecamatan Juwana Tahun 1997-1998. Jurnal Ilmu Sejarah. Universitas Negeri Yogyakarta, Vol. 3, No. 1.

Ulum, Ihyaul. (2016). Batik dan Kontribusinya Terhadap Perekonomian Nasional. Jurnal Bestari.

Wibowo, H.J., dkk. (1990). Pakaian Adat Traadisional Daerah Istimewa Yogyakarta. Jakarta: Depdikbud.

Wulandari, Yosi. (2018). Upaya Pengembangan Pengrajin Batik Di Desa Wisata Batik Gulurejo Kecamatan Lendah Kabupaten
Kulon Progo. Jurnal. Universitas Negeri Yogyakarta, Vol. 7, No. 1.

Wicaksono, Gumirlang. (2012). Meningkatkan Kinerja UMKM Industri Kreatif Melalui Pengembangan Kewirausahaan Dan Orientasi Pasar: Kajian Pada Peran Serta Wirausaha Wanita Di Kecamatan Moyudan, Kabupaten Sleman, Propinsi DIY. Jurnal. Fakultas Ekonomi Universitas Mercu Buana Yogyakarta, Vol. 3, No. 4.

Prasetyo, Yudi. (2017). Sejarah Perkembangan Idustri Batik Sari Kenongo Kecamatan Tulangan Kabupaten Sidoarjo Tahun 19972005. Jurnal Pendidikan Sejarah. Vol. 5, No. 1.

Priandani, Yeni. (2017). Upaya Meningkatkan Keterampilan Motorik Halus Melalui Kegiatan Membatik Di TK Negeri Pembina Galur Kulon Progo. Jurnal. Pendidikan Guru PAUD, Universitas Negeri Yogyakarta, Vol. VI, No. 5.

Munizu, Musran. (2010). Pengaruh Faktor-Faktor Eksternal dan Internal Terhadap Kinerja Usaha Mikro dan Kecil (UMK) di Sulawesi Selatan. Jurnal. Jurusan Manajemen Fakultas Ekonomi Universitas Hasanuddin, Vol. 12, No. 1.

Hermawan, Hary. (2016). Dampak Pengembangan Desa Wisata Nglanggeran Terhadap Ekonomi Masyarakat Lokal. Jurnal Pariwisata. Universitas BSI, Vol. 3, No. 2. 